\title{
ANATOMIA DOS ÓRGÃOS VEGETATIVOS E DO ESCAPO FLORAL DE LEIOTHRIX CRASSIFOLIA (BONG.) RUHL., ERIOCAULACEAE, DA SERRA DO CIPÓ - MG.'
}

\author{
Vera Lucia Scatena ${ }^{2}$ \\ Clélio Lázaro de Melo Rocha ${ }^{3}$
}

Recebido em 27.10.94. Aceito em 29.06.95.

\begin{abstract}
RESUMO: (Anatomia dos órgãos vegetativos e do escapo floral de Leiothrix crassifolia (Bong.) Ruhl., Eriocaulaceae, da Serra do Cipó-MG). L. crassifolia (Eriocaulaceae) é uma planta perene, que cresce nos solos pedregosos e arenosos dos campos rupestres da Serra do Cipó - MG - Cadeia do Espinhaço. Essa planta está exposta a períodos secos e chuvosos, ventos constantes, alta luminosidade e mudanças bruscas de temperatura, características climáticas peculiares dos campos rupestres. Sua caracterização anatômica tem aplicação taxonômica para o grupo e suas estruturas são adaptadas aos fatores ambientais. A raiz apresenta parênquima cortical formado por dois tipos de células, que formam o aerênquima lisígeno, facilitando sua sobrevivência nos solos alagados durante a estação chuvosa. A endoderme é formada for uma única camada de células de paredes espessas. As estrias de Caspary são detectadas somente nos estágios precoces do desenvolvimento da raiz. Chama-se a atenção para a ocorrência de câmaras subestomáticas especiais nas folhas, que podem estar relacionadas com a melhor eficiência das trocas gasosas e constitui uma característica importante para as Eriocaulaceae.
\end{abstract}

Palavras-chave: anatomia; Leiothrix crassifolia; campo rupestre; Eriocaulaceae

\begin{abstract}
Vegetative anatomy and floral scape of Leiothrix crassiflora (Bong.) Ruhl., Eriocaulaceae, from Serra do Cipó-MG). The anatomical characteristics of vegetative organs and floral scape of Leiothrix crassiflora (Eriocaulaceae) were investigated due to their ecological and taxonomic implications for the species. L. crassiflora grows in recently decomposed stony, sandy soils of the Serra do Cipó area of the Espinhaço mountains range, state of Minas Gerais, Brazil. It is found both on wet and dry soils, exposed to constant winds, high light intensities and daily extreme fluctuations of temperature. The root presents a cortical parenchyma with two types of
\end{abstract}

1 Trabalho apresentado no XLV Congresso Nacional de Botânica, São Leopoldo, RS. (Parcialmente subvencionado pela PRPq-UFMG/CNPq).

${ }^{2}$ Departamento de Botânica - IB - UNESP - Caixa Postal 199, 13506-900 Rio Claro, SP, Brasil. Bolsista do CNPq.

${ }^{3}$ Departamento de Botânica - ICB - UFMG - Caixa Postal 486, 31270-110 Belo Horizonte, MG, Brasil. Bolsista FAPEMIG. 
cells that form a lisigenous air parenchyma allowing the plant to survive in wet soils. The endodermis cells present thickened walls. The Casparian strips are shown only by very young roots. Details are given to special leaf substomatal chambers. They are an efficient protection for the gaseous exchange and considered as an important character of the Eriocaulaceae.

Key words: anatomy; Leiothrix crassifolia; rupestrian field; Eriocaulaceae

\section{Introdução}

A família Eriocaulaceae é considerada uma das mais naturais entre as Monocotiledôneas (Eichler 1875). Apresenta distribuição pantropical, havendo poucas espécies nas regiões temperadas (Tomlinson 1969). As Eriocaulaceae incluem cerca de 1.200 espécies reunidas em 10 gêneros, segundo Hensold \& Giulietti (1991). Constituem a comunidade herbácea dominante nos campos rupestres, crescendo principalmente nos solos arenosos, juntamente com Gramineae, Cyperaceae e Xyridaceae (Menezes \& Giulietti 1986).

Por causa do tipo de substrato e da exposição à luminosidade intensa, as plantas de campos rupestres estão sujeitas ao estresse hídrico, mesmo na estação chuvosa, sendo comum observarem-se, nessas espécies, adaptações relacionadas à retenção de água e à sobrevivência em condições extremadas (Joly 1970, Moreira \& Camalier 1977). Uma dessas adaptações pode ser observada em muitas espécies que desenvolveram a capacidade de utilizar a água da neblina, comum nas regiões altas, durante as noites e madrugadas (Menezes 1984).

Leiothrix crassifolia (Bong.) Ruhl. é considerada por Giulietti (1978) uma espécie muito representativa da flora da Serra do Cipó - MG, que corresponde à porção da Cadeia do Espinhaço localizada no Município de Santana do Riacho - MG, distante cerca de $100 \mathrm{~km}$ de Belo Horizonte.

Estudos anatômicos com o gênero Leiothrix foram desenvolvidos por Giulietti (1978, 1984), que apresentou alguns padrões anatômicos dos órgãos vegetativos, e por Monteiro et al. (1985), que mostraram aspectos da estrutura foliar de algumas espécies.

Segundo Stützel (1988) e Scatena (1990), as espécies de Eriocaulaceae que apresentam as raízes com o parênquima cortical constituído por aerênquima são aquelas que crescem em solos encharcados.

Segundo Malmanche (1919), Tomlinson (1969), Giulietti (1978), Castro (1986) e Scatena (1990), os rizomas das Eriocaulaceae apresentam organização anatômica com córtex sem um sistema vascular independente, mas percorrido por traços foliares e radicais.

Com relação ao mesofilo, as folhas das Eriocaulaceae apresentam nervuras que são mais ou menos paralelas e são formadas por feixes líbero-lenhosos envoltos por duas bainhas (Tomlinson 1969, Giulietti 1978, Monteiro et al. 1984, 1985 e Castro 1986). Segundo Scatena (1990), em Syngonanthus, a bainha externa é de origem endodérmica e a bainha interna, de origem pericíclica.

Este trabalho tem como objetivo caracterizar anatomicamente os órgãos 
vegetativos e o escapo floral de L. crassifolia, para facilitar a delimitação taxonômica da espécie, bem como interpretar suas possíveis adaptações anatômicas ao ambiente.

\section{Material e métodos}

Os indivíduos de L. crassifolia (Bong.) Ruhl. foram coletados nos campos rupestres da Serra do Cipó, município de Santana do Richo, MG. Foram utilizados 20 indivíduos de duas populações distintas. O testemunho de cada população estudada está depositado no Herbário BHCB do Departamento de Botânica do ICB - UFMG: V.L. Scatena \& J.P. Lemos Filho (BHCB 19611); C.L.M. Rocha \& V.L. Scatena (BHCB 22 732).

O material coletado, foi fixado em FAA segundo Johansen 1940, porém utilizando etanol a $50^{\circ} \mathrm{GL}$, para estudos anatômicos. Foram feitas secções à mão livre na região mediana dos órgãos estudados e submetidas ao processo de dupla coloração com fuccina básica e azul de astra (Roeser 1962) e montadas em gelatina glicerinada. Também foram utilizados cortes histológicos seriados, obtidos com o micrótomo rotativo Jung 2.030 Biocut, com $10 \mu \mathrm{m}$ de espessura a partir de peças incluídas em parafina, segundo técnicas usuais indicadas por Sass (1951). A dissociação da epiderme foi feita segundo o método de Jeffrey (Johansen 1940).

Para análise histoquímica, o amido foi identificado pelo emprego da solução de lugol (Sass 1951); materiais graxos, em geral, pelo sudan IV (Johansen 1940); a lignina pela solução de fluoroglucina em meio ácido (Johansen 1940), pelo azul de toluidina (Feder \& O'Brian 1968), pelo verde iodo (Dop \& Gautié 1909) e pela fucsina (Roeser 1962); a celulose pelo cloreto de zinco iodado (Strasburger 1911), pelo azul de toluidina (Feder \& O'Brian 1968), pelo vermelho congo (Dop \& Gautié 1909) e pelo azul de astra (Roeser 1962). Esta análise, para o tecido de sustentação dos escapos e das folhas foram realizadas nos órgãos jovens e adultos.

\section{Resultados}

L. crassifolia é uma planta herbácea de porte reduzido, apresenta rizoma oblíquo ramificado ou não, achatado, de onde saem as folhas dispostas em roseta e os escapos florais distribuídos alternadamente e, na porção mais inferior, saem as raízes adventícias (Figura 1). O rizoma é envolvido por bainhas foliares persistentes nas porções mais velhas e nas mais jovens é envolvido por tricomas alvos.

A raiz jovem, seccionada transversalmente próximo ao ápice, apresenta-se com os tecidos diferenciados (Figura 2). No nível em que os tecidos já estão totalmente diferenciados (Figura 3), nota-se a epiderme unisseriada com células de paredes finas (Figuras 3, 6-7). Os pêlos radicais apresentam-se isolados ou aos pares e suas bases são menores do que aquelas células epidérmicas que não constituem pêlos (Figura 7).

A exoderme é unisseriada, com células de paredes finas (Figuras 3, 6-7). O parênquima cortical, desde a fase de diferenciação, é formado por células braciformes que, na maturidade, apresentam paredes espessadas (Figuras 3 e 6). Entre as células 


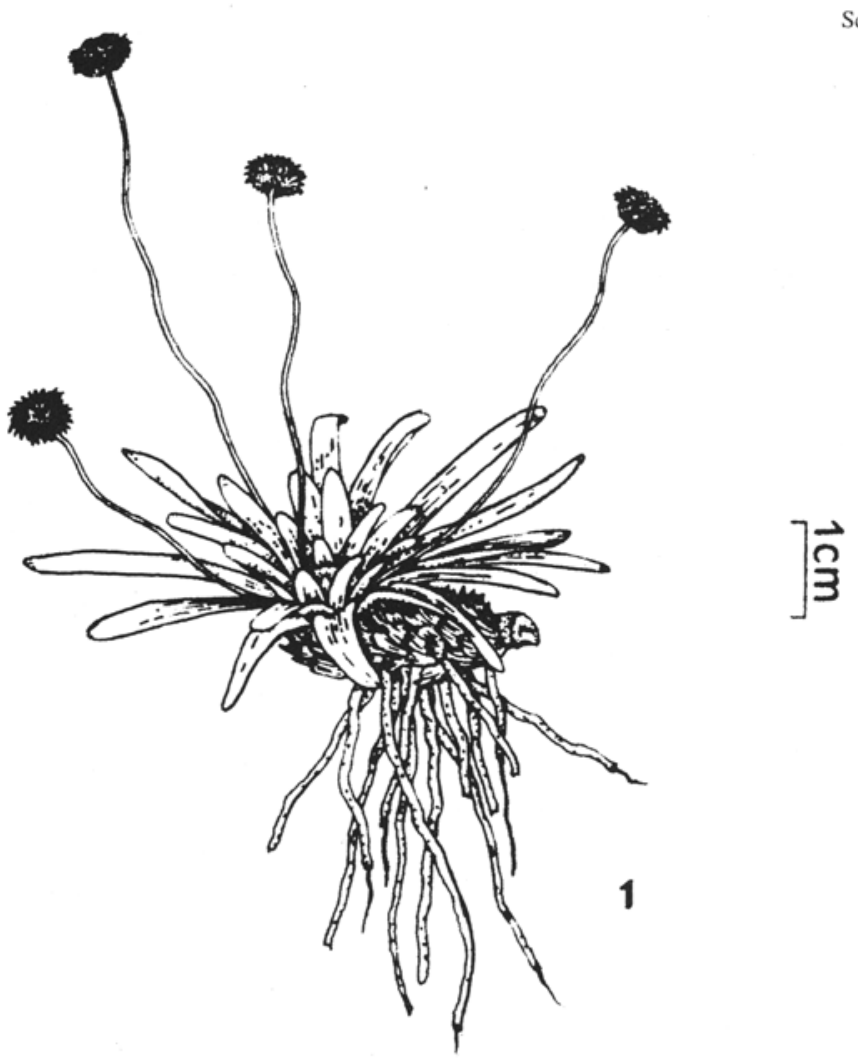

Figura 1 - Aspecto geral de Leiothrix crassifolia (Bong.) Ruhl.

braciformes, encontram-se células maiores do que elas, cujas paredes tangenciais e transversais se rompem (Figuras 3 e 6 - setas), formando grandes espaços que reservam ar, constituindo um parênquima aerífero lisígeno. Essa organização, vista em secção longitudinal da raiz, mostra que as paredes radiais dessas células grandes mantêm-se aderidas às paredes das células braciformes em toda sua extensão (Figuras 5 e 8 setas), formando lamelas longitudinais superpostas quando desaparecem as paredes tangenciais e transversais dessas células grandes. O córtex das raízes de $L$. crassifolia possui espessura maior quando comparado ao diâmetro do cilindro central (Figuras 89), sendo que ele é facilmente destacado e removido no manuseio dessas raízes. A endoderme é unisseriada, com paredes alongadas no sentido tangencial, cujas estrias de Caspary só podem ser observadas na fase em que os tecidos estão se diferenciando (Figura 2 - setas). Na maturidade, essas células se apresentam com as paredes bem espessadas (Figuras 3-4, 6 e 10).

O periciclo, na fase de diferenciação (Figura 2), apresenta-se unisseriado e com paredes finas, sofrendo espessamento na maturidade da raiz (Figuras 4 e 10). O cilindro 

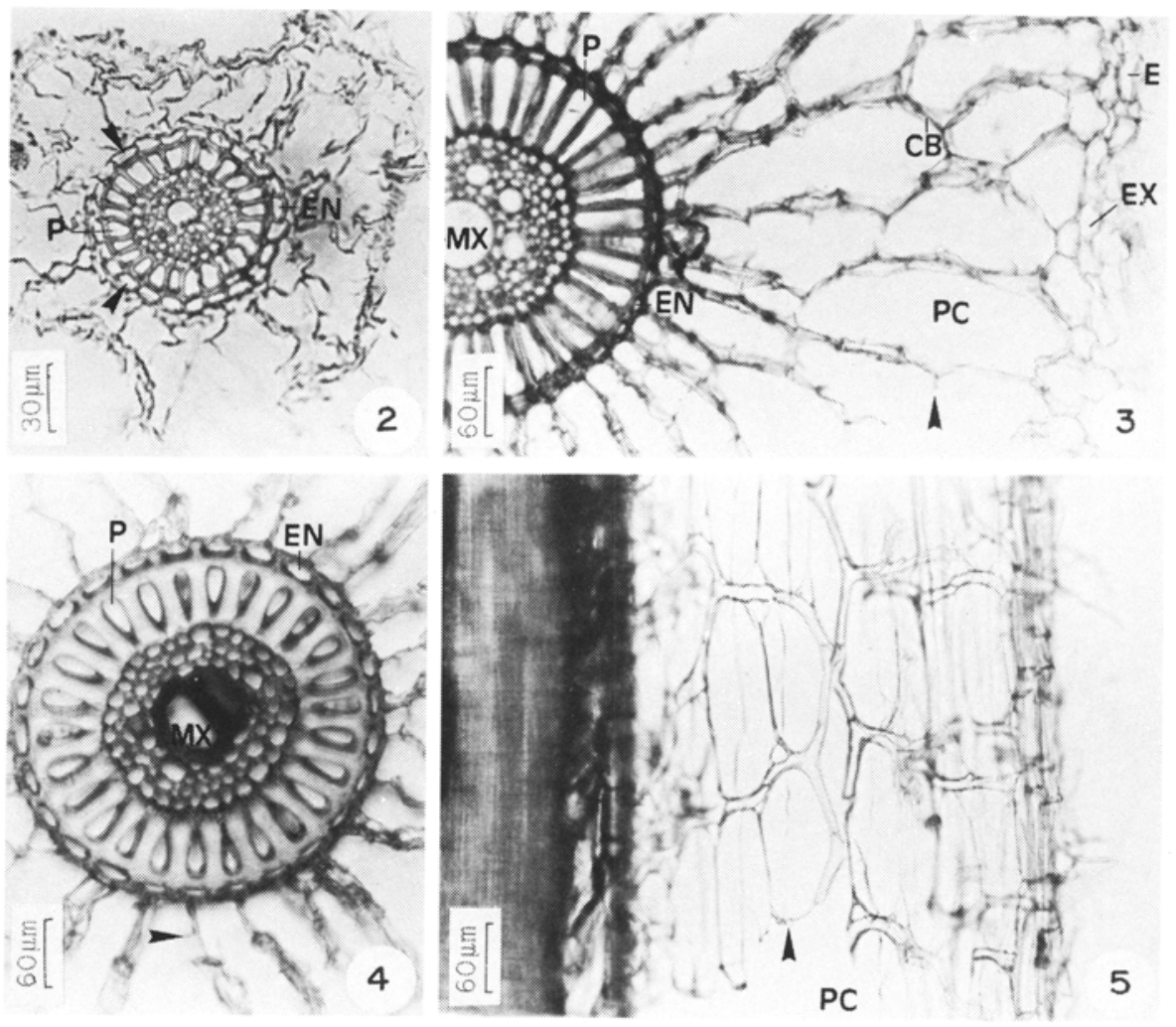

Figuras 2-5 - Seç̧ões transversais (Figuras 2-4) e longitudinal (Figura 5) de raízes de L. crassifolia. Figura 2 - raiz jovem, região próxima ao ápice com os tecidos diferenciados. Figura 3 - região com os tecidos totalmente diferenciados. Figura 4 - detalhe do cilindro vascular. Figura 5 - secção longitudinal da raiz. (CB- célula braciforme, E- epiderme, EN- endoderme, EX-exoderme, MX- metaxilema, Ppericiclo, PC- parênquima cortical).

vascular, que é delimitado pela endoderme, apresenta estrutura poliarca com um único elemento de metaxilema (Figuras 3 e 10) ou, ocasionalmente, dois (Figura 4).

Pode-se observar as características morfológicas internas do rizoma de $L$. crassifolia, através dos diagramas das secções transversais nos níveis basal, mediano e apical, respectivamente (Figuras 11, 13 e 15). Nesses diagramas, notam-se duas regiões distintas: a região periférica, que constitui o córtex com vários traços foliares e raízes adventícias, e a região central, que corresponde ao cilindro vascular. Ambas estão nitidamente separadas por um meristema (Figuras 11, 13 e 15). Esse meristema, que separa o córtex do cilindro vascular, é constituído por células de paredes finas no início do desenvolvimento do caule, e de paredes espessadas nas regiões maduras do mesmo. Nota-se também nesses diagramas, uma maior concentração dos tecidos vasculares na periferia do cilindro vascular. A Figura 12 representa detalhe do feixe 

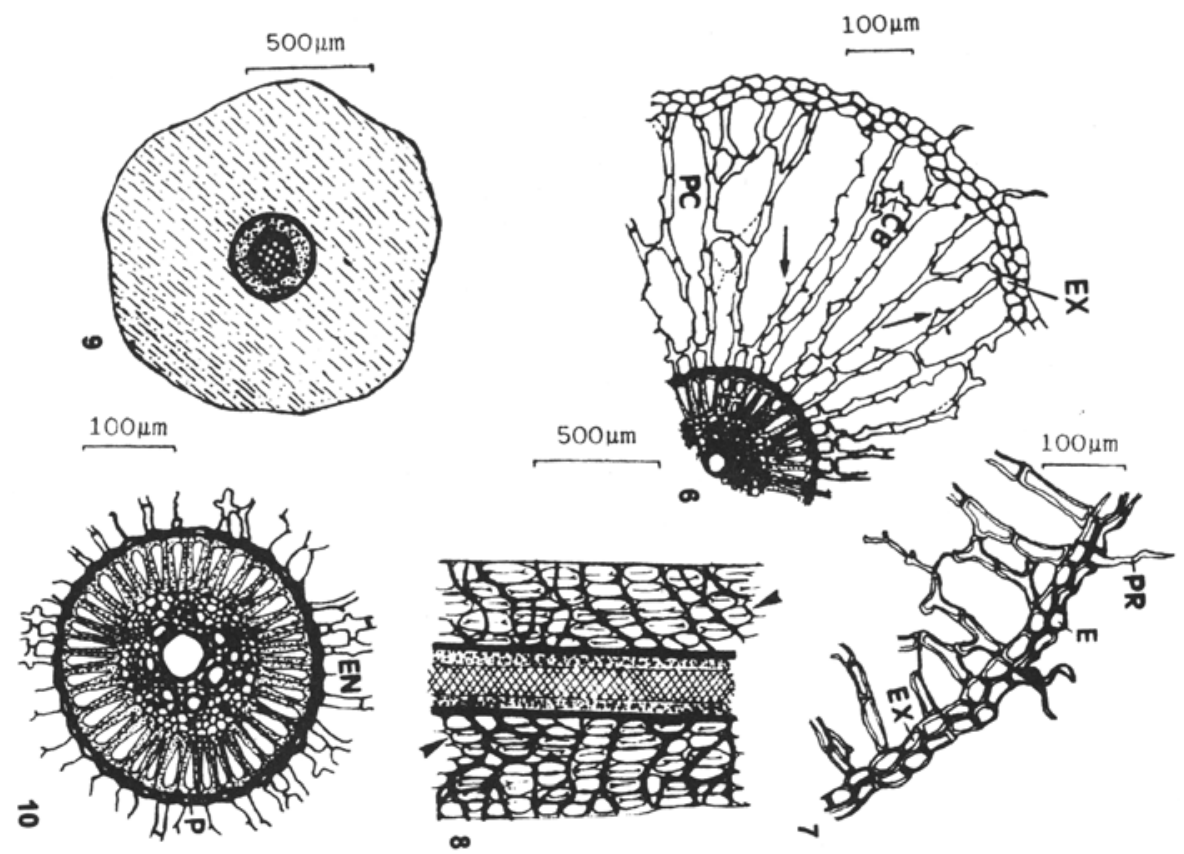

Cilindro vascular

Epiderme

$\sqsupseteq$ Endoderme

.0. Feixes vasculares

Parênquima

Parênquima clorofiliano

[2] Parênquima cortical

0 Periciclo e Meristema

(- Raiz adventícia

Figuras 6-10 - Secções de raízes de L. crassifolia. Figura 6 - secção transversal. As setas apontam para os fragmentos das paredes das células maiores que foram lisadas. Figura 7 - detalhe da seç̧ão transversal da epiderme e exoderme. Figura 8 - diagrama longitudinal. Observam-se as células maiores do córtex íntegras (setas). Figura 9 - diagrama transversal ilustrando as dimensões relativas do córtex e do cilindro vascular. Figura 10 - detalhe do cilindro vascular. (CB- célula braciforme, E- epiderme, EN- endoderme, EXexoderme, P- periciclo, PC- parênquima cortical, PR-pêlo radicular). 
anfivasal, característico da região central do cilindro vascular. A Figura 14 representa um feixe vascular periférico próximo ao meristema.

O parênquima cortical é revestido por epiderme unisseriada e possui parênquima amilífero (Figura 16). Este não apresenta tecidos vasculares próprios, a não ser os traços foliares que o atravessam e as raízes adventícias intracorticais (Figuras 11, 13, 15 e 17) em diferentes estágios de desenvolvimento. Na região próxima ao ápice, os entrenós são extremamente reduzidos e o rizoma é inclinado. A estrutura desse caule é irregular, onde na parte superior da secção, os tecidos estão distribuídos longitudinalmente e na parte inferior da mesma os tecidos estão distribuídos transversalmente (Figura 17). Nesta figura observa-se ainda a presença de tricomas caulinares que crescem a partir das células epidérmicas.

Basalmente, cada escapo é envolvido por uma bráctea curta, de estrutura anatômica similar à de uma folha verde (Figura 19), onde se observa a epiderme, o parênquima clorofiliano intercalado por células parenquimáticas de paredes espessas e pelos feixes vasculares (Figuras 18-19). Os escapos, em seção transversal, apresentam contorno poligonal devido à presença de costelas de sustentação, variando de 3 a 4 (Figuras 20-22), conforme o indivíduo. As costelas correspondem aos tecidos de sustentação (esclerênquima) mais o parênquima clorofiliano. Entre duas costelas formase uma reentrância chamada sulco (Figuras 20-22).

A epiderme é unisseriada e suas células possuem a parede periclinal externa mais espessada que a interna (Figura 22). Os estômatos estão situados em frente ao parênquima clorofiliano nas costelas (Figuras 20-22) e possuem câmaras subestomáticas especiais, que são delimitadas por células de paredes espessas curtas e longas no plano transversal, dependendo da altura que o corte se deu nessas células (Figura 22 - setas).

O córtex, de estrutura radiada, é constituído pelas costelas e pelos sulcos (Figuras 20-22). A endoderme é contínua (Figura 20) ou descontínua (Figura 21-22), unisseriada, formando calotas nos feixes vasculares menores.

Internamente à endoderme, está o periciclo contínuo, de forma estrelada, isolando para fora os feixes vasculares menores que são totalmente envolvidos por ele e os maiores apenas parcialmente, pelo lado externo (Figuras 20-22). Todos os feixes vasculares são colaterais, com metaxilema bem desenvolvido (Figuras 20-22). Nos feixes vasculares maiores são observadas as lacunas de protoxilema. A medula é parenquimática e pode apresentar células de paredes delgadas ou espessas.

O resultado da análise histoquímica, realizada para determinar a composição do tecido de sustentação que ocorre nos escapos e nas folhas, resultou negativo para os reagentes cloreto de zindo iodado e para floroglucina em meio ácido e positivo apenas para os corantes: azul de toluidina, verde iodo e fucsina.

$\mathrm{Na}$ folha, a epiderme, em vista frontal, apresenta células alongadas no sentido longitudinal, intercaladas por células curtas (Figuras 23-24). Os estômatos ocorrem apenas na face abaxial e são paracíticos, com duas células subsidiárias (Figura 24). O padrão anatômico das folhas, em secções transversais, mostra uma disposição intercalada de feixes vasculares maiores e menores (Figuras 27-28) ou os feixes vasculares todos do mesmo tamanho (Figuras 25-26), apresentando descontinuidade 


\section{总}
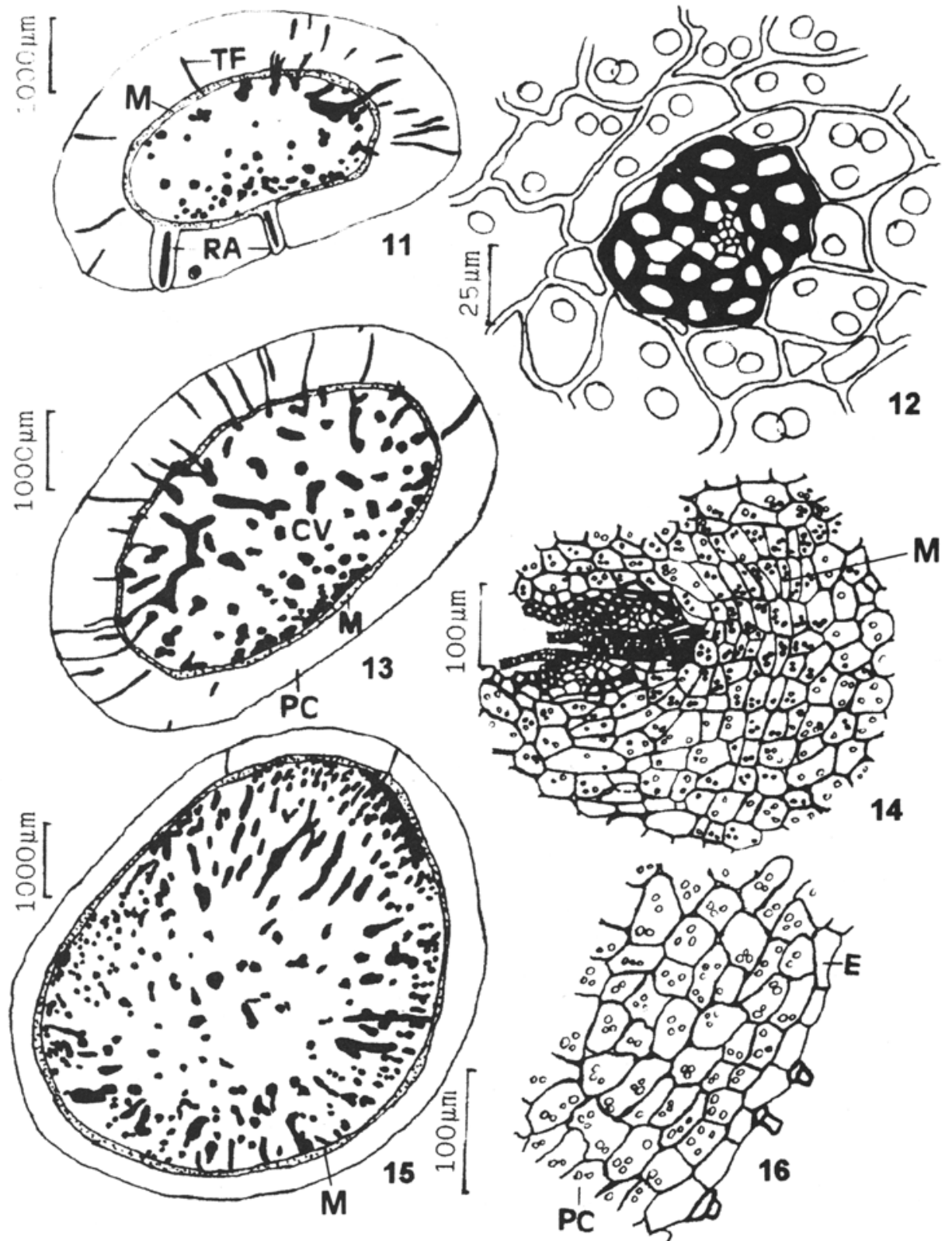

Figuras 11-16 - Diagramas e desenhos de secções transversais feitas na porção basal (Figuras 11-12), mediana (Figuras 13-14) e apical (Figuras 15-16) do caule de L. crassifolia. Na figura 12 observa-se o detalhe de um feixe vascular anfivasal. Na figura 14 observa-se detalhe do feixe vascular indo em direção ao meristema (M) e, na figura 16, observa-se detalhe da epiderme (E) e do parênquima cortical (PC). (Eepiderme, M- meristema, PC- parênquima cortical, RA- raiz adventícia, TF- traço foliar). 


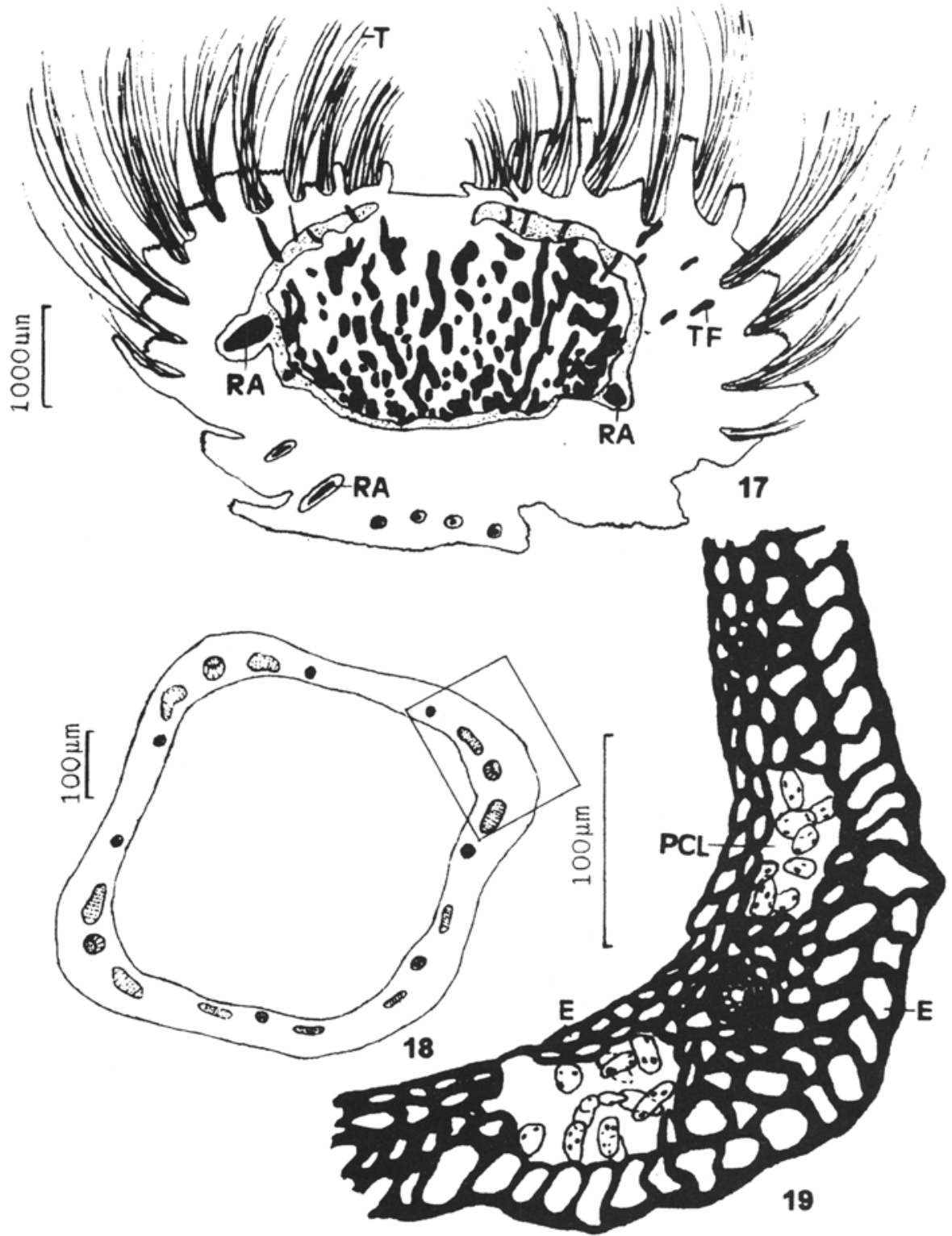

Figuras 17-19 - A figura 17 é um diagrama do ápice caulinar de L. crassifolia. Figura 18 - diagrama da seç̧ão transversal da região mediana da bráctea do escapo floral. Figura 19 - detalhe da bráctea. (Eepiderme, PCL- parênquima clorofiliano, RA- raiz adventícia, T- tricoma, TF- traço foliar). 

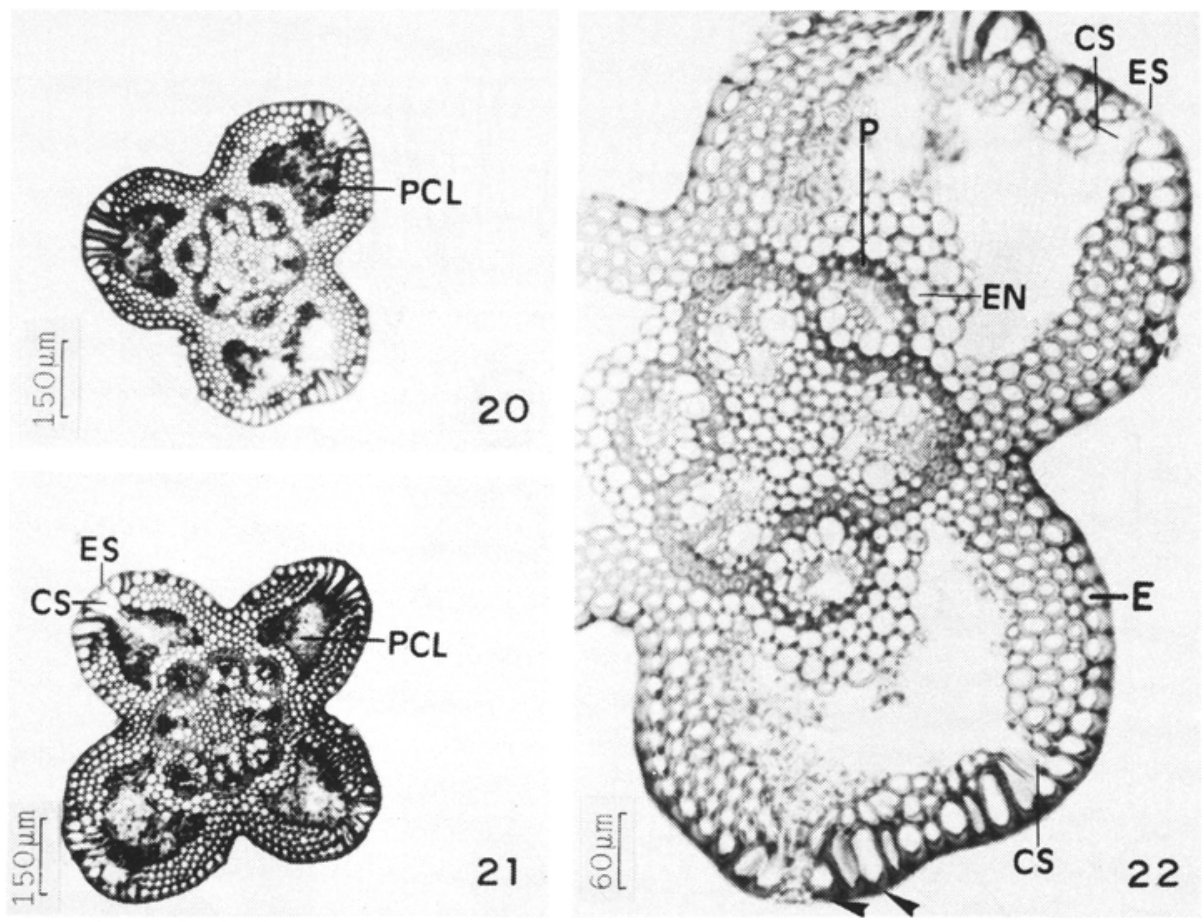

Figuras 20-22 - Secções transversais da região mediana de escapos florais de L. crassifolia. Figura 20 escapo com três costelas. Figura 21 - escapo com 4 costelas. Na figura 22 observa-se detalhe da figura 20. (CS- câmara subestomática, E- epiderme, EN- endoderme, ES- estômato, P- periciclo, $\mathrm{PCL}$ - parênquima clorofiliano).

lateral do mesofilo (Figuras 25-28). Essa descontinuidade é devida às extensões das bainhas dos feixes vasculares (Figuras 25-26) ou à presença de hipoderme mais as extensões de bainhas (Figuras 27-28). As extensões das bainhas podem se dirigir para ambas as faces (feixes maiores) ou somente para a face adaxial (feixes menores) da epiderme (Figuras 25-28).

A face adaxial da epiderme, em seção transversal, apresenta células retangulares, sendo a parede periclinal externa mais espessada que a interna (Figuras 25-28). Observase na figura 25 (seta) uma célula basal de tricoma caduco, que ocorre com baixa freqüência. A face abaxial da epiderme apresenta células alongadas ao nível das costelas e curtas ao nível dos sulcos (Figuras 25-28). Os estômatos formam uma câmara subestomática especial. Esses estômatos se alinham em séries ou fileiras nas regiões das costelas da folha.

Chama-se a atenção para a presença de células de paredes espessadas, distituídas de cloroplastos, curtas e longas, na região dos estômatos, que formam a câmara subestomática especial. Em secção transversal à folha, observam-se essas células 

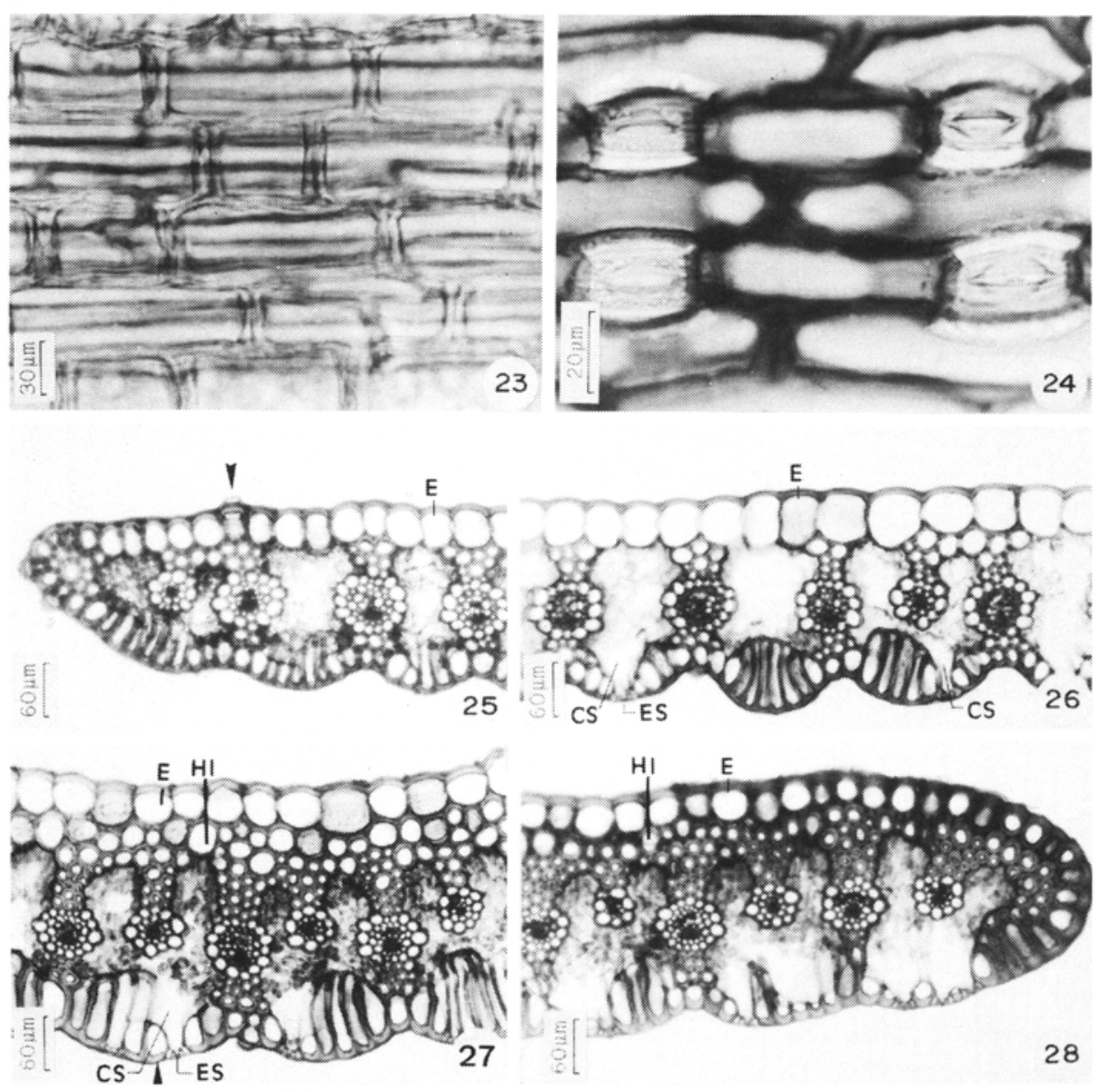

Figuras 23-28 - Vista frontal da epiderme de folha de L. crassifolia; face adaxial (Figura 23) e face abaxial (Figura 24). Figuras 25-28 - secções transversais da região mediana de folhas de L. crassifolia. (CScâmara subestomática, E- epiderme, ES- estômato, HI- hipoderme).

epidérmicas de formas variadas, curtas e longas (Figura 29 - setas). Em secção paradérmica à folha, observa-se que essas células constituem verdadeiras estruturas de sustentação abaixo dos estômatos (Figura 30 - setas). Em secções longitudinais à folha, essas células apresentam-se intercaladas com os estômatos e possuem a forma da letra i minúscula e $\underline{U}$ maiúscula com a base reta (Figuras 31-32). Notam-se numerosas pontoações nas paredes das células epidérmicas, principalmente na face adaxial, onde ocorrem os tricomas (Figura 31 - setas).

O mesofilo é formado por parênquimas paliçádico na face adaxial, esponjoso na face abaxial, embora não haja uma diferenciação muito nítida entre eles. 


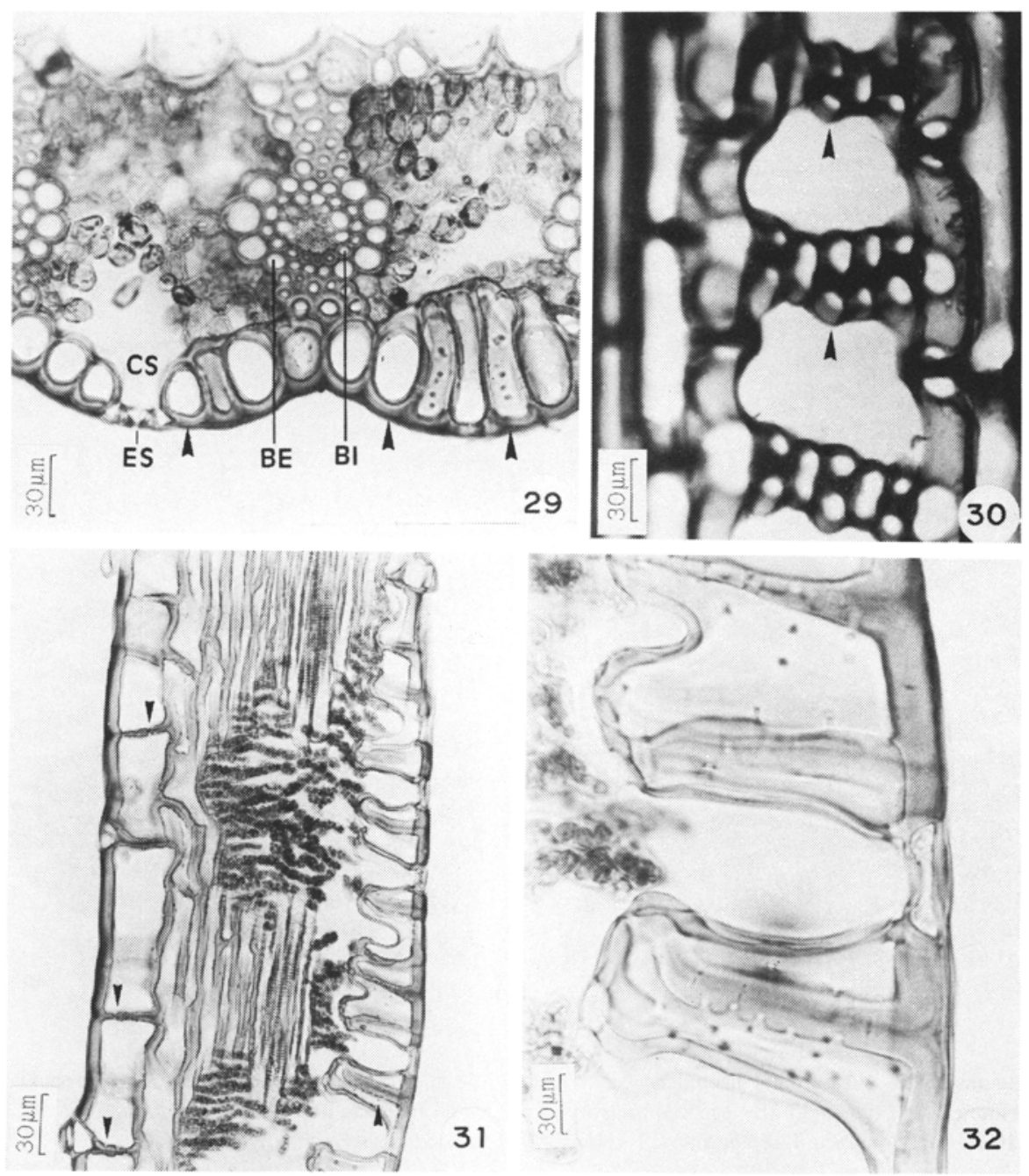

Figuras 29-32 - Secção transversal da região mediana do mesofilo de L. crassifolia (Figura 29). A estrutura que a câmara subestomática forma é vista em secções paradérmica (Figura 30) e longitudinais (Figuras 31-32). (BE- bainha externa do feixe vascular, BI- bainha interna do feixe vascular, CS- câmara subestomática, ES- estômato).

Os feixes vasculares são colaterais, sendo os maiores envolvidos por bainha dupla, isto é, uma bainha externa e uma bainha interna (Figuras 25-29). A bainha externa é parenquimática, com células de paredes levemente espessadas e de natureza endodérmica (Figuras 25-29). A bainha interna é formada, na maioria dos casos, por 
células de paredes espessadas e de natureza pericíclica (Figura 29). Nos feixes menores, o espessamento das paredes das células da bainha interna é progressivamente menor, podendo estar ausente em alguns pontos, com elementos do xilema e/ou floema tocando diretamente a bainha externa, ou seja, a endoderme (Figuras 25-28).

$\mathrm{O}$ bordo das folhas pode ser agudo (Figura 25) ou obtuso (Figura 28), ambos contendo de 2 a 3 camadas de tecido de sustentação (esclerênquima), logo abaixo da epiderme.

\section{Discussão}

L. crassiflora cresce nos solos arenosos e pedregosos dos campos rupestres de Minas Gerais, que se tornam alagados durante a estação chuvosa. Suas raízes adventícias são do tipo vermiforme articulada, como descrito por Malmanche (1919) e Tomlinson (1969) para algumas Eriocaulaceae. As raízes de Eriocaulaceae que possuem córtex com diafragmas de células braciformes foram observadas por Hare (1950) e Tomlinson (1969) em Eriocaulon; por Giulietti $(1978,1984)$ em Eriocaulon e Leiothrix; por Stützel (1988) em Leiothrix, Mesanthenmun e Rondonanthus; e por Scatena (1990) em Syngonanthus. As células braciformes encontradas no córtex radicular de $L$. crassifolia são homólogas às células estreladas descritas por Stützel (1988) para Eriocaulon magnificum; bem como são homólogas às células braciformes de espécies de Syngonanthus descritas por Scatena (1990). Entre essas células braciformes estão as células intermediárias, que são maiores, achatadas, cujas paredes tangenciais se rompem, formando corredores de ar no parênquima cortical, como observado também por Stützel (1988) e Scatena (1990) para outras Eriocaulaceae, com a diferença que para L. crassifolia, forma aerênquima lisígeno, definido segundo Fahn (1990).

$\mathrm{O}$ acúmulo de ar nessas raízes pode estar relacionado à ação do etileno. Sabese que em solos encharcados ocorre diminuição da concentração de oxigênio no solo, seguida do aumento da concentração de etileno nas raízes (Smith \& Russel 1969). No ambiente em que $L$. crassifolia cresce, o solo fica encharcado durante a estação chuvosa.

O etileno estimula a produção de celulase que desintegra as paredes das células (Moore 1979). Essa atuação pode ser diferencial, decorrente da presença de células competentes à ação do hormônio. O que provavelmente acontece no parênquima cortical de L. crassifolia é uma atuação diferencial do etileno que estimula a produção de celulase que, por sua vez, desintegra as paredes tangenciais das células não-braciformes, formando assim, os corredores de ar, concordando com o descrito para as raízes de Syngonanthus por Scatena (1990), com a diferença de que aqui esse espaço é um aerênquima lisígeno.

Tomlinson (1969) reconhece nas raízes de Eriocaulaceae três zonas corticais, assim estabelecidas: córtex externo, córtex médio e córtex interno. No córtex da espécie estudada, não se observam essas três zonas, pois o que Tomlinson (1969) denomina de camada cortical interna, neste trabalho reconheceu-se como endoderme e o que ele denomina de camada endodermóide, neste trabalho reconheceu-se como periciclo. A exoderme corresponde ao córtex externo. 
Os autores que estudaram raízes de diferentes gêneros de Eriocaulaceae, como Malmanche (1919), Tomlinson (1969), Giulietti (1978, 1984), Castro (1986) e Stützel (1988) não se referiram à presença de estrias de Caspary na endoderme das espécies por eles estudadas. Já, Scatena (1990) observou essa estrutura em espécies de Syngonanthus.

Nas raízes das plantas adultas de L. crassifolia, a endoderme possui as células com paredes espessadas. Só foi possível observar as estrias de Caspary em porções muito jovens das raízes, quando os tecidos ainda estavam na fase de diferenciação. Em analogia ao que foi observado em Syngonanthus por Scatena (1990), na determinação das estruturas das raízes, propõem-se, neste trabalho a determinação de endoderme e periciclo, ao invés de córtex interno e camadas endodermóides, respectivamente utilizadas por outros autores.

No rizoma, observa-se um córtex sem sistema vascular independente, conforme indicado por Tomlinson (1969), Castro (1986) e Scatena (1990) para outras Eriocaulaceae que apresentam rizoma. Há no córtex, feixes vasculares, constituindo os traços foliares e, também, raízes adventícias, conforme descrito por aqueles autores. Em concordância com o observado em Yucca por Diggle \& De Mason (1983a e b), em Xyris por Sajo (1992), em várias monocotiledôneas por Rudall (1991) e em Syngonanthus por Scatena (1990), o cilindro vascular é formado por plexos vasculares periféricos, que provavelmente se originam do PTM-Primary Thickening Meristem, ou seja, Meristema de Espessamento Primário (MEP) e estão localizados internamente a ele. O MEP também dá origem às raízes adventícias e apresenta células de paredes delgadas que contornam toda a periferia do cilindro vascular. $\mathrm{O}$ termo aqui utilizado, MEP, corresponde ao Periciclo, empregado para algumas espécies de Syngonanthus por Scatena \& Menezes (1995).

Na maioria dos representantes de Eriocaulaceae, os caules são pubescentes com longos tricomas filamentosos na axila das folhas (Hensold 1988). Tricomas que crescem a partir da epiderme do rizoma foram observados em $L$. crassifolia, formando uma densa cobertura no ápice do mesmo.

As brácteas que recobrem a base dos escapos em outras espécies do gênero Leiothrix (Giulietti 1978, 1984) são anatomicamente similares às folhas verdes, característica esta também observada para L crassifolia.

A variação do número de costelas (de 3 a 4) nos escapos de $L$. crassifolia pode estar relacionada à variação intra e interpopulacional na área de estudo.

$\mathrm{O}$ resultado da composição do tecido de sustentação que ocorre nos escapos e nas folhas de L. crassifolia foi negativo quando se utilizou floroglucina em meio ácido, reagente normalmente utilizado em trabalhos de anatomia vegetal, que se detecta com clareza a presença de lignina. Foi negativo também para celulose com cloreto de zinco iodado. Com esses resultados antagônicos, para confirmar a presença de lignina utilizaram-se os corantes azul de toluidina, verde iodo e fucsina com resultado positivo. Este tecido deve ser esclerênquima, mais especificamente fibras septadas, cujas paredes contêm lignina de composição variada. Esta composição variada da lignina também foi observada nas células do parênquima aquífero de Pleurothallis rupestris - 
Orchidaceae (Scatena, não publicado) onde utilizou-se tratamento especial, com auxílio de microscópio de fluorescência. Tanto $L$. crassifolia como $P$. rupestris ocorrem amplamente nos campos rupestres do Brasil e talvez por viverem em condições climáticas tão adversas típicas desse ecossistema, ressaltando a alta luminosidade, essas plantas apresentem essa variação na composição da lignina.

Nas folhas de L. crassifolia, observou-se cutícula delgada, a despeito do caráter xeromórfico que representa o espessamento da parede tangencial externa das células epidérmicas. Esse espessamento também foi encontrado em Paepalanthus por Castro (1986) e em Syngonanthus por Scatena (1990), e, segundo Pyykkö (1966), deve estar relacionado com ambientes secos e pode proteger a folha contra a transpiração e luminosidade excessivas, pois $L$. crassifolia cresce nos campos rupestres e fica continuamente exposta à alta luminosidade. Castro (1986) discute que no ápice caulinar e na base de folhas, das espécies de Paepalanthus que estudou, os tricomas poderiam ser absorventes, permitindo a essas espécies o aproveitamento da água disponível em forma de neblina, embora seus resultados não tenham sido conclusivos. Em $L$. crassifolia também se observam esses tricomas com pontoações nas paredes da célula basal que podem estar exercendo a função de absorver água.

Na região dos estômatos, o formato das células leva à ocorrência de câmaras subestomáticas especiais que formam verdadeiras estruturas de sustentação e devem estar relacionadas com a necessidade de manutenção dos espaços de ar para melhor eficiência das trocas gasosas. Essa estrutura foi descrita anteriormente para outras espécies de Leiothrix por Giulietti (1978) e por Monteiro et al. (1985) como sendo células buliformes. Neste trabalho, não se utilizou essa denominação, pois essas células de paredes espessas não estão envolvidas com as modificações da superfície foliar, como seria a função das células buliformes, e sim estão envolvidas com a manutenção dos espaços de ar nas câmaras subestomáticas. Em L. crassifolia, essa estrutura é semelhante àquela câmara subestomática especial descrita por Castro \& Menezes (1990) para espécies de Paepalanthus. Concorda-se aqui com a interpretação apresentada por Scatena \& Menezes (1993) para espécies de Syngonanthus, que na família Eriocaulaceae há necessidade de manutenção das câmaras subestomáticas íntegras, com reserva de ar, o que não é comum de se ver nas outras plantas.

Segundo Fahn \& Cutler (1992), as câmaras subestomáticas amplas estabelecem um longo gradiente de difusão entre o parênquima clorofiliano e o meio ambiente, além de uma alta resistência à difusão, contribuindo, mesmo quando os estômatos estão totalmente abertos, para baixas taxas de transpiração. Assim, aceita-se que a presença de câmaras subestomáticas especiais seja uma característica anatômica importante para as Eriocaulaceae, uma vez que já foi descrita para as espécies dos gêneros Paepalanthus, Syngonanthus e agora, Leiothrix, embora com padrões anatômicos diferentes, a interpretação fisiológica é a mesma.

Feixes vasculares foliares envolvidos por bainha dupla são considerados característicos para Eriocaulaceae (Tomlinson 1969; Giulietti 1978; Monteiro et al. 1985; Castro 1986 e Scatena 1990). Em L. crassifolia, por homologia aos tecidos da raiz, do caule e do escapo, infere-se que a bainha externa é de origem endodérmica e 
a bainha interna, de origem pericíclica, em concordância às conclusões similares feitas por Scatena (1990) com espécies de Syngonanthus.

A disposição dos feixes vasculares nas folhas dos indivíduos estudados é do tipo paralela, apresentando variação quanto à presença ou não de feixes menores intercalados aos feixes maiores. Giulietti (1978) não se refere à intercalação de feixes maiores e menores nos exemplares de Leiothrix que estudou. Essa autora registrou que todos os feixes se alinhavam num mesmo nível entre as superfícies adaxial e abaxial, porém mais próximos à superfície abaxial. Em L. crassifolia os feixes vasculares menores são ligeiramente deslocados para a superfície adaxial, em relação aos feixes maiores.

Notam-se variações anatômicas nos indivíduos estudados, como o número de costelas e o espessamento ou não das células parenquimáticas da medula, nos escapos. Nas folhas, o bordo pode ser agudo ou obtuso, pode apresentar ou não tecido de sustentação, a hipoderme pode estar ausente ou presente, os feixes vasculares podem ou não ser do mesmo tamanho. Essas variações encontradas aos níveis intra e interpopulacionais devem-se provavelmente ao isolamento dessa espécie nas diferentes montanhas da Serra do Cipó-MG.

\section{Agradecimentos}

Ao Conselho Nacional de Desenvolvimento Científico e Tecnológico (CNPq) pela concessão de Auxílio e Bolsa de Pesquisa (Proc. 510062-92-0; 520116/94). À Dra. Ana Maria Giulietti pela identificação do material; à Sra. Carmem S.C. Ragghiante e Célia M. Hebling pela digitação; ao Sr. Luiz Roberto Jordão, pelo auxílio na confecção das pranchas.

\section{Referências bibliográficas}

Castro, N.M. 1986. Estudos morfológicos dos órgãos vegetativos de espécies de Paepalanthus Kunth. (Eriocaulaceae) da Serra do Cipó (Minas Gerais). São Paulo: Universidade de São Paulo: Inst. de Biociências.

Castro, N.M. \& Menezes, N.L. 1990. Considerações sobre a natureza das células altas da epiderme abaxial das folhas de Paepalanthus Kunth. Eriocaulaceae. Bolm. Bot. Univ. S. Paulo 12: 95-100.

Diggle, P.K. \& De Manson, D.A. 1983a. The relationship between the primary thichening meristem and the secondary thichening meristem in Yucca whipplei Torr. I: Hystology of the mature vegetative stem. Amer. J. Bot. 70: 1195-1204.

Diggle, P.K. \& Manson, D.A. 1983b. The relationship between primary thickening meristem and secondary thickening meristem in Yucca whipplei Torr. II: Ontongenetic relationship within the vegetative stem. Amer: J. Bot. 70: 1205-1216.

Dop, P. \& Gautié, A. 1909. Manual de techinique botanique. Paris: F.R. de Rudeval.

Eichler, A.W. 1875. Blüthendiagramme. Leipzig: Willhelm Engelmam.

Fahn, A. 1990. Plant Anatomy: 4ª ed. Oxford: Pergamon Press.

Fahn, A. \& Cutler, D.F. 1992. Xerophytes. Berlim: Gebrüder Borntrager.

Feder, N. \& O’Brian, T.P. 1968. Plant microtechnique: some principles and new methods. Amer: J. Bot. 55(1): 123-142. 
Giulietti, A.M. 1978. Os gêneros Eriocaulon L. e Leiothrix Ruhl. (Eriocaulaceae) na Serra do Cipó. Minas Gerais, Brasil. Tese de Doutorado. Universidade de São Paulo. Inst. de Biociências.

Giulietti, A.M. 1984. Estudos taxonômicos do gênero Leiothrix Ruhl. (Eriocaulaceae). Tese de Livre Docência. Universidade de São Paulo. Inst. de Biociências.

Hare, L.C. 1950. The structure and development of Eriocaulon septangulare With. J. Linn. Soc. Bot. 53 : 422-448.

Hensold, N. 1988. Morphology and systematic of Paepalanthus subgenus Xeractis (Eriocaulaceae). Michigan: The American Society of Plants Taxonomists. Sistematic Botany Monographs. vol. 23.

Hensold, N. \& Giulietti, A.M. 1991. Revision and redifinition of the genus Rondonanthus Herzog (Eriocaulaceae). Ann. Miss. Bot. Gard. 78: 441-459.

Joahnsen, D.A. 1940. Plant microthechinique. New York: Mc Grall-Hill Bood Co.

Joly, A.B. 1970. Conheça a vegetação brasileira. São Paulo: EDUSP, Editora Polígono.

Malmanche, L.A. 1919. Contribution a l'étude anatomique des Eriocaulacées et des families voisines. Restiacées, Centrolepidacées, Xyridacées, Philydracées, Mayacacées. Paris. St. Clond. Tese.

Menezes, N.L. 1984. Características anatômicas e a filogenia na família Velloziaceae. Tese de Livre Docência. Universidade de São Paulo. Inst. de Biociências.

Menezes, N.L. \& Giulietti, A.M. 1986. Serra do Cipó, paraíso dos botânicos. Cienc. Hoje 4: 38-44.

Monteiro, W.R.; Giulietti, A.M. \& Castro, M.M. 1984. Aspects of leaf structure of some species of Eriocaulon L. (Eriocaulaceae) from Serra do Cipó (Minas Gerais, Brasil). Revta. bras. bot. 7: 137147.

Monteiro, W.R.; Castro, M.M. \& Giulietti, A.M. 1985. Aspects of leaf structure of some species of Leiothrix Ruhl. (Eriocaulaceae) from Serra do Cipó (Minas Gerais, Brazil). Revta. bras. Bot. 7: 109-125.

Moore, T.C. 1979. Biochemistry and Physiology of plant hormones. New York: Edit. Thomas C. Moore.

Moreira, A.A.N. \& Camalier, C. 1977. Relevo. In: Geografia do Brasil. Região Sudeste. Rio de Janeiro: IBGE 3: 1-50.

Pyykkö, M. 1966. The leaf anatomy of East patagonian xeromorphic plants. Ann. Bot. Fenn. 3: 453-622.

Roeser, K.R. 1962. Die Nadel der Schwarzkiefer-Massenprodukt und Kunstwert der Natur. Mikrokosmos 61: 33-36.

Rudall, P. 1991. Lateral meristems and stem thickening growth in Monocotyledons. Bot. Rev. 57(2): 150163.

Sajo, M.G. 1992. Organização vascular do caule em Xyris L. (Xyridaceae). Bolm. Bot. Univ. S. Paulo 13: 49-66.

Sass, J.E. 1951. Botanical microtechnique. 2nd. eds. Iowa: The Iowa State College Press.

Scatena, V.L. 1990. Morfoanatomia de espécies de Syngonanthus Ruhl. (Eriocaulaceae) dos Campos Rupestres do Brasil. Tese de Doutorado. Universidade de São Paulo. Int. de Botânica.

Scatena, V.L. \& Menezes, N.L. 1993. Consideração sobre a natureza da câmara subestomática e das células epidérmicas das folhas de Syngonanthus Ruhl., seção Thysanocephalus Koern. (Eriocaulaceae). Revta. bras. bot. 16(2): 159-165.

Scatena, V.L. \& Menezes, N.L. 1995. Aspectos morfológicos e anatômicos de caules de Syngonanthus Ruhl. Eriocaulaceae. Bolm. Bot. Univ. S. Paulo 14:19-107.

Smith, K.A. \& Russel, R.S. 1969. Occurrence of ethylene and its significance in anaerobic soil. Nature 22: 769-771.

Strasburger, E. 1911. Handbook of Pratical Botany. 7th. ed. Translated from the german by W. Hillhouse. London: George Allen \& Company Ltd.

Stützel, T. 1988. Untersuchungen zur Wurzelanatomie der Eriocaulaceen. Flora 180: 223-239.

Tomlinson, P.B. 1969. Commelinales-Zingiberales. In: Metcalfe, C.R. (ed.) Anatomy of the Monocotyledons. Oxford: Clarendon Press. Vol. 3, p. 1-446. 